\title{
CLIMA URBANO: O USO DE MODELOS GEOESPACIAIS NA INVESTIGAÇÃO DO COMPORTAMENTO TÉRMICO EM JUIZ DE FORA- MG
}

\author{
PIMENTEL, Franciele Oliveira Pimentel - tiele_pimentel@yahoo.com.br \\ Universidade Federal de Juiz de Fora / UFJF
}

\author{
FERREIRA, Cássia de Castro Martins - cassia.castro@ufjf.edu.br \\ Universidade Federal de Juiz de Fora / UFJF
}

\begin{abstract}
RESUMO: A preocupação com os chamados impactos ambientais urbanos fomentou um maior interesse nas pesquisas, principalmente aquelas voltadas para as análises climáticas, na escala urbana. A cidade por consequência de seu processo de organização e estruturação desenvolveu um clima totalmente particular, o clima urbano. Isso é possível através da retirada da vegetação original e a inserção dos chamados equipamentos urbanos, como por exemplo, as vias impermeabilizadas, as construções, a verticalização, além da circulação de pessoas e veículos que irão contribuir para um maior aquecimento da atmosfera local. Os materiais presentes no meio urbano vão apresentar diferentes valores de albedo, emissividade, absortividade e irradiação e consequentemente, estes condicionarão diferentes valores de temperatura de superfície e que influenciarão na temperatura do ar. O presente estudo tem por objetivo analisar o comportamento do clima urbano na cidade de Juiz de Fora- MG, onde foram trabalhadas 35 regiões urbanas. $O$ estudo desenvolvido permite estimar o potencial de aquecimento a partir de variáveis de um modelo geomatemático, como albedo, emissividade, massa construída e altura de edificações urbanas. Este conjunto de dados permitiu alcançar uma visualização de como se distribuem os distintos campos térmicos na cidade. Para fins de validação do modelo, foi feita uma correlação estatística entre o modelo matemático proposto, o qual gerou um mapa de potencial de aquecimento e a temperatura de superfície obtida na faixa do infravermelho termal. O modelo utilizado provou possuir consistência para ser adaptado a fim de ser replicado em diferentes cidades com especificidades térmicas além de ser viável a integração de outras informações e dados.
\end{abstract}

PALAVRAS-CHAVE: Campos Térmicos, Clima Urbano, Modelo Climático.

URBAN CLIMATE: THE USE OF GEOSPACIAL MODELS IN THE RESEARCH OF THERMAL BEHAVIOR IN JUIZ DE FORA- MG

\begin{abstract}
Concern about so-called urban environmental impacts has fostered greater interest in research, especially those focused on climate analyzes, on the urban scale. The city as a consequence of its process of organization and structuring has developed a totally particular climate, the urban climate. This is possible through the removal of the original vegetation and the insertion of so-called urban facilities, such as waterproofed roads, constructions, verticalization, as well as the circulation of people and vehicles that will contribute to a greater warming of the local atmosphere. The materials present in the urban environment will present different values of albedo, emissivity, absorptivity and irradiation and, consequently, these will condition different values of surface temperature and that will influence the air temperature. The objective of this study is to analyze the urban climate city of Juiz de Fora- MG, where 35 urban areas were worked. The study aims to estimate the potential for heating from variables of a geospatial model, such as albedo, emissivity, mass and height of urban buildings. This dataset allowed us to obtain a visualization of how the different thermal fields are distributed in the city. For purposes of model validation, a statistical correlation was made between the proposed mathematical model, which generated a map of the heating potential and the surface temperature obtained in the thermal infrared range. The model used proved to have consistency to be adapted in order to be replicated in different cities with thermal specificities besides being feasible the integration of other information and data.
\end{abstract}

KEYWORDS: Thermal Fields, Urban Climate,Climatic Model. 


\section{INTRODUÇÃO}

O clima sempre foi alvo de discussões por ser uma variável que afeta (in)diretamente o cotidiano das pessoas. Nas últimas décadas os estudos sobre o clima das cidades vêm ganhando ainda mais destaque dentro da comunidade científica, principalmente nos países centrais. Os motivos são principalmente os ligados às questões das mudanças climáticas e também por afetar diretamente a saúde dos habitantes. Em 2003, ondas de calor intenso na Europa preocuparam os gestores públicos, devido a grande quantidade de mortes principalmente de idosos e crianças, além de grande número de internações decorrentes das temperaturas intensas.

Diferentemente dos países centrais, onde a urbanização se deu de forma mais gradativa e planejada o processo de urbanização brasileira foi intenso e concomitante ao crescimento da industrialização, acompanhado de um grande êxodo rural ocorrido nas últimas décadas. A busca da população por melhores oportunidades de vida nas cidades e a fuga da precariedade oferecida pelo campo, fez com que milhares de brasileiros se direcionassem para as cidades resultando assim na formação de grandes regiões metropolitanas, onde Monteiro (2015 p.85) afirma que "o improvisado (ilegal) superava, de muito, o planejado (legal), o caos superando a ordem". De acordo com o Instituto Brasileiro de Geografia e Estatística (IBGE), hoje cerca de $90 \%$ dos brasileiros residem nas cidades, o que caracterizou o século XX como o "século da urbanização", enquanto o XXI seria o "século da cidade". Mendonça (2003).

A cidade de Juiz de Fora, localizada na Zona da Mata de Minas Gerais (mapa 1), não fica fora dessas estatísticas, pois vêm apresentando nas últimas três décadas um crescimento populacional considerável, quando se compara os dados apresentados pelo IBGE de 1980 a população era de 307.534 habitantes, já em 2010 esse número salta para 517.872 habitantes.

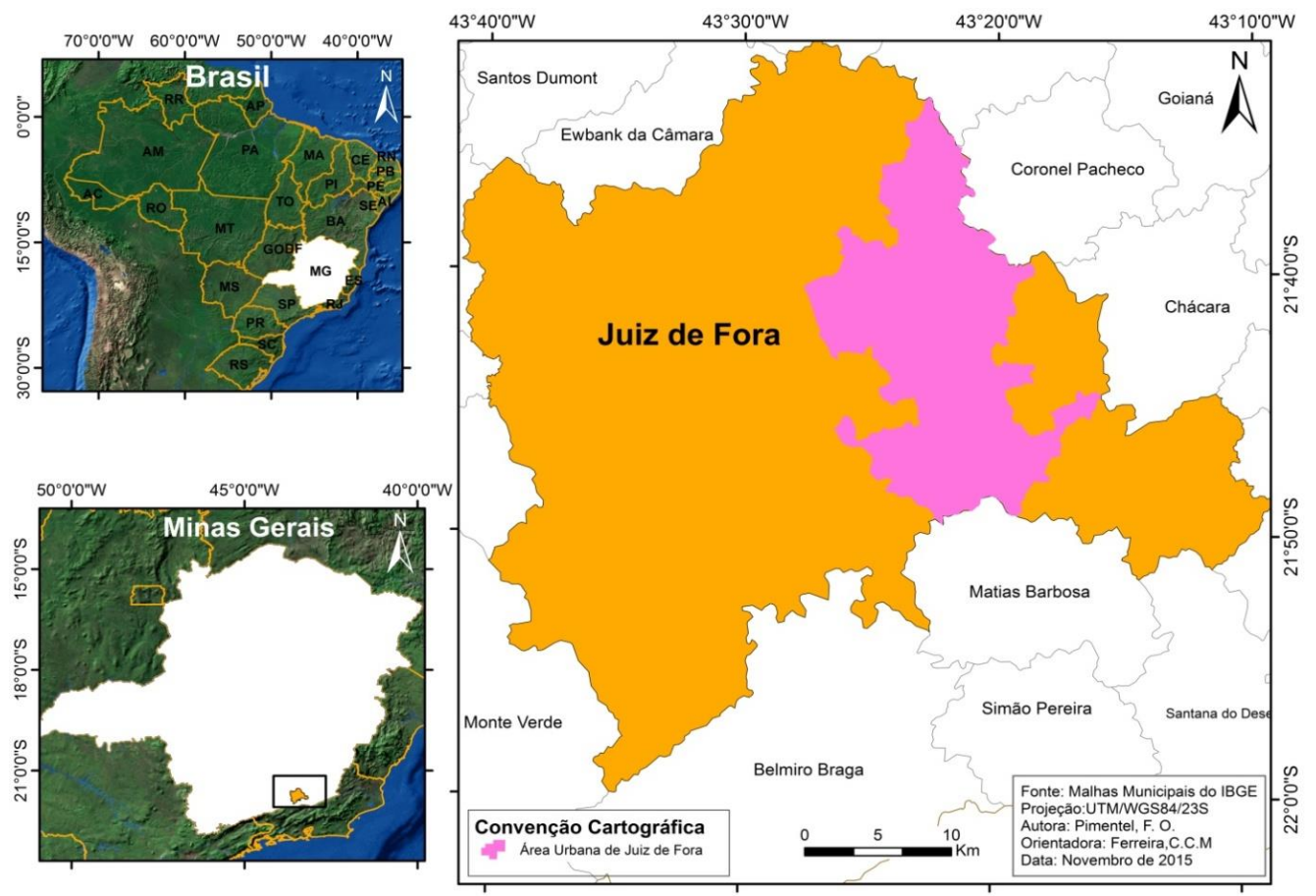

MAPA 1 - Localização do Município de Juiz de Fora. 
O município de acordo com o Plano Diretor de Desenvolvimento Urbano (PDDU, 2004), regido pela Lei Municipal no 9.811 de Junho de 2000; possui uma área total de $1.429,875 \mathrm{~km}^{2}$, dos quais $444,551 \mathrm{~km}^{2}$ estão na área urbana e $983,324 \mathrm{~km}^{2}$ na área rural. A área urbana possui uma população de 516.247 habitantes (IBGE, 2010), sendo que 98,9\% deste total é população urbana, e apenas $1,1 \%$ de rural.

Essa concentração populacional no meio urbano vai transformar a maneira como se organiza aproveitamento do solo, refletindo no aumento do volume do adensamento em razão das edificações, das vias, da circulação de veículos, da supressão da vegetação local, modificando a estrutura Sistema Clima Urbano. (S.C.U).

Nessa perspectiva, esta pesquisa tem por objetivo a aplicação de um modelo geomatemático capaz de integrar as variáveis (albedo, emissividade, massa construída altura das edificações, cobertura vegetal e corpos d'água), que irão influenciar na criação de diferenciados campos térmicos, podendo indicar os possíveis locais com maior ou menor potencial de aquecimento. A área a qual foi escolhida para o desenvolvimento dessa pesquisa, compreende 35 regiões urbanas (Mapa 2), que estão localizadas ao longo do percurso do Rio Paraibuna, no sentindo noroeste-sudeste. Essa escolha se deu em função da menor amplitude altimétrica encontrada nessas regiões, pois o fator altimetria poderia vir a contribuir para aumentar as diferenças térmicas.

A caracterização do sítio urbano local de Juiz de Fora, onde está localizada a área de estudo, pode ser classificada como um fundo de vale, estando presente a planície do Rio Paraibuna e nas adjacências alguns morros bordeando o vale.

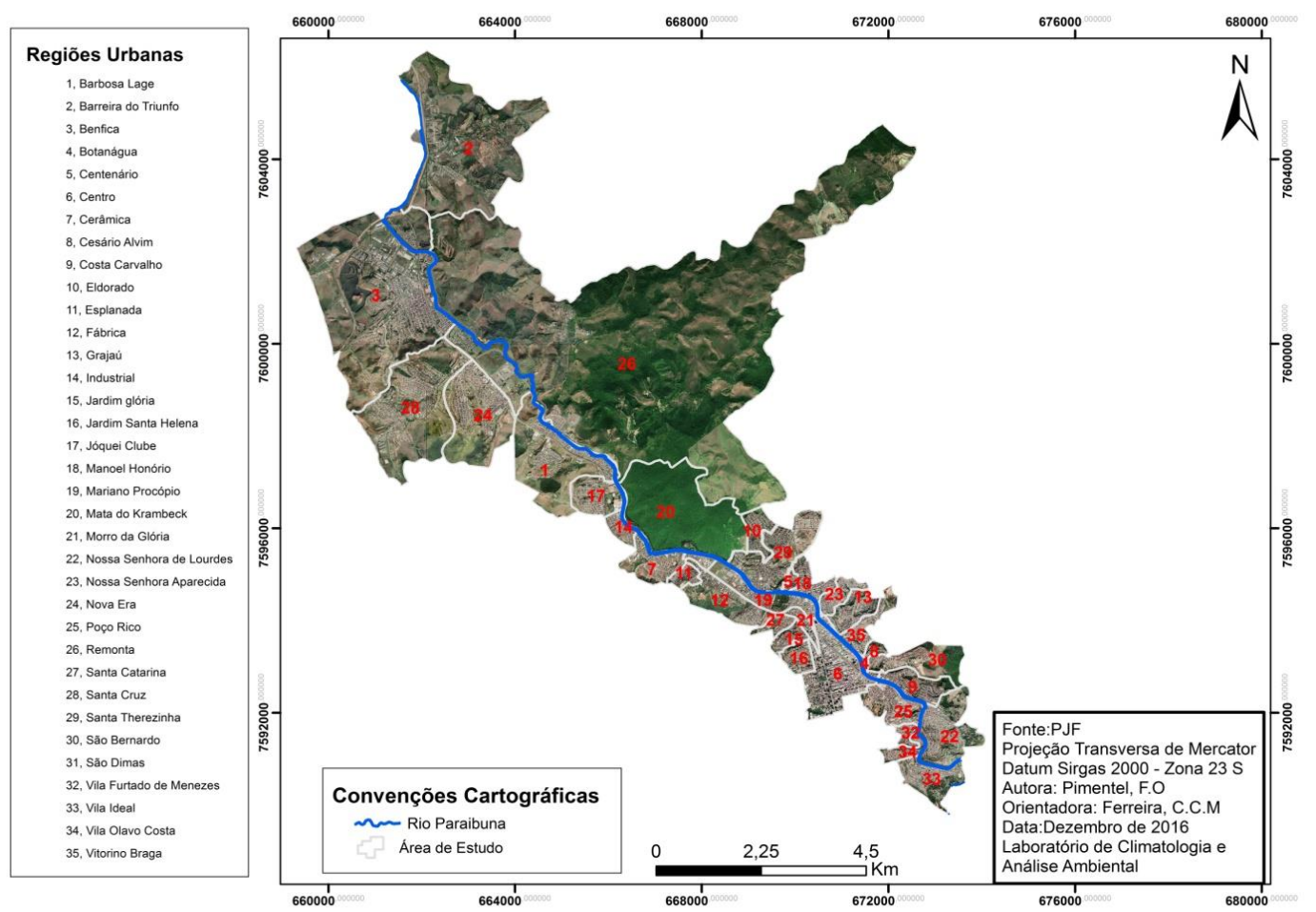

MAPA 2 - Localização das 35 regiões urbanas escolhidas para a área de estudo 


\section{MATERIAIS E MÉTODOS}

As etapas para essa pesquisa consistiram na organização de um amplo banco de dados geocodificados (disponibilizado em partes pela Prefeitura Municipal de Juiz de Fora) sobre as 35 regiões urbanas escolhidas para a investigação. Além da elaboração do material cartográfico-temático. Todo o processo de mapeamento das variáveis para confecção dos mapas básicos, que deram origem aos mapas temáticos e que por fim deram origem ao mapa síntese foi desenvolvido no software ArcGis 10.2.

No quadro 1 , têm-se uma organização por etapa de cada variável que foi sendo utilizada e reclassificada para chegar ao mapa síntese.

QUADRO 1 - Orientação para confecção de mapas básicos e temáticos.

\begin{tabular}{|c|c|c|}
\hline Mapas Básicos & Mapas Temáticos & Mapa Final \\
\hline Altura das Edificações & \multirow{2}{*}{$\begin{array}{l}\text { Massa Construída } \\
\text { Absoluta } \\
\text { Massa Construída } \\
\text { Relativa } \\
\text { Altura das Edificações }\end{array}$} & \multirow{5}{*}{$\begin{array}{l}\text { Potencial de } \\
\text { Aquecimento }\end{array}$} \\
\hline Número de Pavimentos & & \\
\hline $\begin{array}{l}\text { Revestimento das } \\
\text { Edificações }\end{array}$ & \multirow[t]{2}{*}{$\begin{array}{l}\text { Albedo } \\
\text { Emissividade }\end{array}$} & \\
\hline $\begin{array}{l}\text { Cobertura das } \\
\text { Edificações }\end{array}$ & & \\
\hline $\begin{array}{l}\text { Tamanho das Áreas } \\
\text { Verdes e Corpos Hídricos }\end{array}$ & $\begin{array}{l}\text { Áreas Verdes e Corpos } \\
\text { Hídricos }\end{array}$ & \\
\hline
\end{tabular}

Fonte: Adaptado de Ferreira (2014)

As informações de cada lote/edificação foi espacializada, posteriormente foram utilizadas na confecção dos mapas básicos, que deram origem aos mapas temáticos. Em seguida foram associados a um modelo proposto por Ferreira (2014), no qual foram atribuídos pesos a cada variável conforme seu grau de influência no aquecimento ou resfriamento, com o objetivo de espacializar e identificar áreas potencialmente formadoras de ilhas de calor.

Para o processo de confecção do mapa de potencial de aquecimento, o primeiro passo foi a aquisição das informações das camadas de lotes das 35 regiões urbanas escolhidas para área de estudo. Na tabela de atributos do shapefile camada de lotes foram criados campos para armazenamento das informações de cada lote. O primeiro campo se referiu ao tipo de cobertura de cada edificação, o segundo campo constituiu no número de pavimentos dessas 
construções. Foi criada uma codificação, para cada tipo de cobertura, sendo esta atribuída a uma numeração, como pode ser visualizada no quadro 2 .

QUADRO 2 - Codificação para cada tipo de cobertura

\begin{tabular}{|l|l|}
\hline \multicolumn{1}{|c|}{ Tipo de Cobertura } & \multicolumn{1}{c|}{ Código Atribuído } \\
\hline Não se aplica & 0 \\
\hline Fibrocimento & 1 \\
\hline Telha Cerâmica & 2 \\
\hline Telha Metálica & 3 \\
\hline Laje & 4 \\
\hline
\end{tabular}

Para o campo pavimentos foi atribuído um número exato de andares de acordo com cada edificação, não sendo contabilizado como pavimento sobreloja e nem terraços cobertos, pois na maior parte das ocorrências não possuem paredes ou colunas de concretos em suas laterais, ou são subterrâneos. Algumas regiões urbanas, principalmente as de ocupação irregular, ou construções posteriores a 2007, época em que foi realizado o levantamento aerofotogramétrico, não foram cadastradas pela Prefeitura de Juiz de Fora. Desse modo para completar o banco de dados e não ter falhas nas informações das variáveis foi realizada a identificação das mesmas e criado polígonos delimitando esses lotes e inserindo as informações nos campos. Assim as regiões urbanas tiveram cada edificação identificada na imagem aérea e com o auxílio Software Street View, contido no Google Earth Pro, foi visualizada cada variável, como pode ser observado na figura 1.

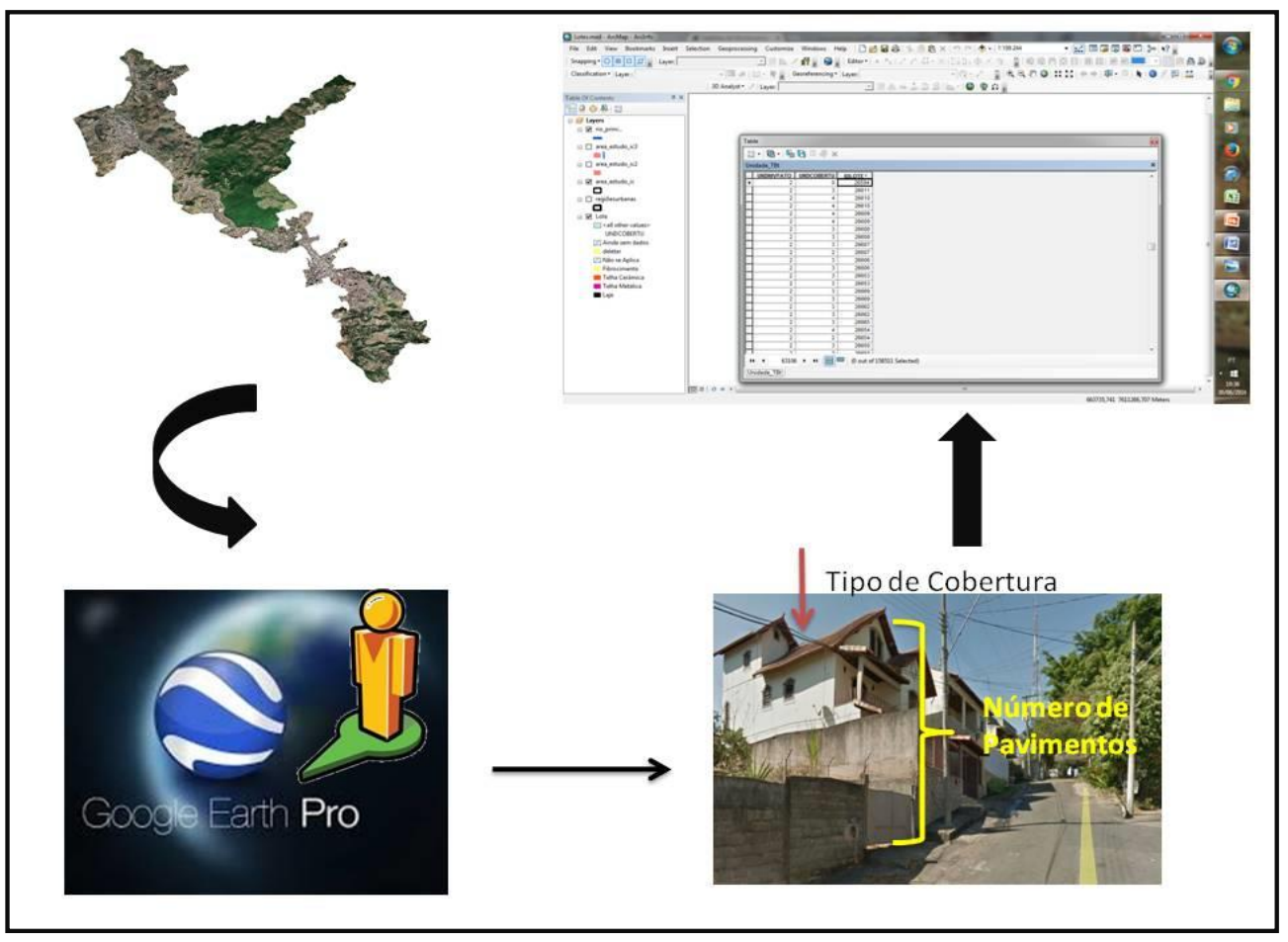

Figura 1 - Esquema da organização do banco de dados. 


\subsection{ALBEDO E EMISSIVIDADE}

Depois do preenchimento das variáveis de cada lote, foram inseridas as informações de albedo e emissividade de cada variável. Na tabela de atributos no menu "selecionar atributos", foi selecionada cada tipo de cobertura e criado mais dois campos para ser adicionado os valores de albedo e emissividade, conforme o quadro 3 .

QUADRO 3 - Organização dos valores e Albedo e Emissividade.

\begin{tabular}{|l|l|l|}
\hline \multicolumn{1}{|c|}{ Tipo de Cobertura } & \multicolumn{1}{c|}{ Albedo } & \multicolumn{1}{c|}{ Emissividade } \\
\hline Não se aplica & 0 & 0 \\
\hline Fibrocimento & 0,34 & 0,9 \\
\hline Telha Cerâmica & 0,53 & 0,9 \\
\hline Telha Metálica & 0,57 & 0,25 \\
\hline Laje & 0,26 & 0,9 \\
\hline Vegetação & 0,18 & 0,96 \\
\hline
\end{tabular}

\section{2 - ALTURA DAS EDIFICAÇÕES}

Em seguida foi criado mais um campo na tabela de atributos, para ser gerado o campo de altura das edificações através da variável número de pavimentos, para tal adotou-se como altura média de cada pavimento 3,0 metros.

\section{3 - MASSA CONSTRUÍDA}

A massa construída é um dos fatores indispensáveis nos estudos de investigação do clima urbano, pois será protagonista no desequilíbrio do balanço de energia, pois é responsável pela estocagem de grande parte da radiação solar incidente, isso em função dos tipos materiais que compõem as construções. Contudo, essa variável ainda é muito pouco explorada em pesquisas desenvolvidas por geógrafos sobre o clima urbano.

Nessa pesquisa adotaremos essa variável de forma quantitativa, baseando-se na proposta desenvolvida por Tso (1989). Essa variável é obtida por uma equação que calcula em kg a massa de construção de cada edificação existente na área urbana. Esse modelo foi aplicado por ele na cidade de Kuala Lumpur, na Malásia, e apontou uma correlação entre o aumento da massa construída e o aumento da temperatura do ar nas áreas centrais da cidade.

A massa construída pode ser calculada através das seguintes equações proposta Tso (1989):

Eq.(1) $\quad M C=V c t \times \lambda c / A f$

Em que: 
Vct: Volume do concreto $\left(\mathrm{m}^{3}\right)$

$\lambda c:$ Densidade do concreto $=2400 \mathrm{Kg} / \mathrm{m}^{3}$

Af: Área total da fração urbana

O volume do concreto deve ser calculado pela seguinte equação:

Eq. (2) Vct $=($ Per $\times \mathrm{H} \times \mathrm{Ec1})+($ Apr $\times \mathrm{NL} \times \mathrm{Ec} 2)$

Em que:

Per: perímetro da edificação $(\mathrm{m})$

H: altura da edificação (m)

Ec1: Espessura média do concreto nas construções, adotado como 0,20 m. para as paredes externas.

Apr: projeção da edificação $\left(m^{2}\right)$

NL: Número de lajes +1

Ec2: Espessura média do concreto nas construções, adotado como 0,10 m. para as lajes.

Para fins de simplificação Tso (1989) admitiu que a massa construída se constituísse unicamente de concreto para homogeneizar e facilitar os cálculos.

Para obter os dados de massa construída total, foi criado um campo na tabela de atributos para ser adicionado o valor da área edificada, que foi calculada através da ferramenta "calcular geometria". Em seguida foi criado mais um campo para que fosse adicionado o valor do perímetro das edificações, e dessa forma mais dois campos foram criados para utilizar as equações 1 e 2 . Em seguida foi somada a massa construída de cada edificação contida dentro de cada região urbana.

\subsection{MAPA SÍNTESE DE POTENCIAL DE AQUECIMENTO}

Para elaborar o mapa final de Potencial de Aquecimento, a cada variável já levantada foi atribuído um peso, pois este modelo propõe a atribuição de pesos para cada uma das variáveis, que vai levar em conta o potencial de aquecimento ou resfriamento de cada uma delas. No quadro 4, podemos visualizar a distribuição dos pesos conforme as variáveis destacadas para esse estudo. Em seguida esses pesos foram somados estabelecendo a capacidade das áreas em serem potencialmente quentes ou frescas. 
QUADRO 4 - Variáveis e Pesos.

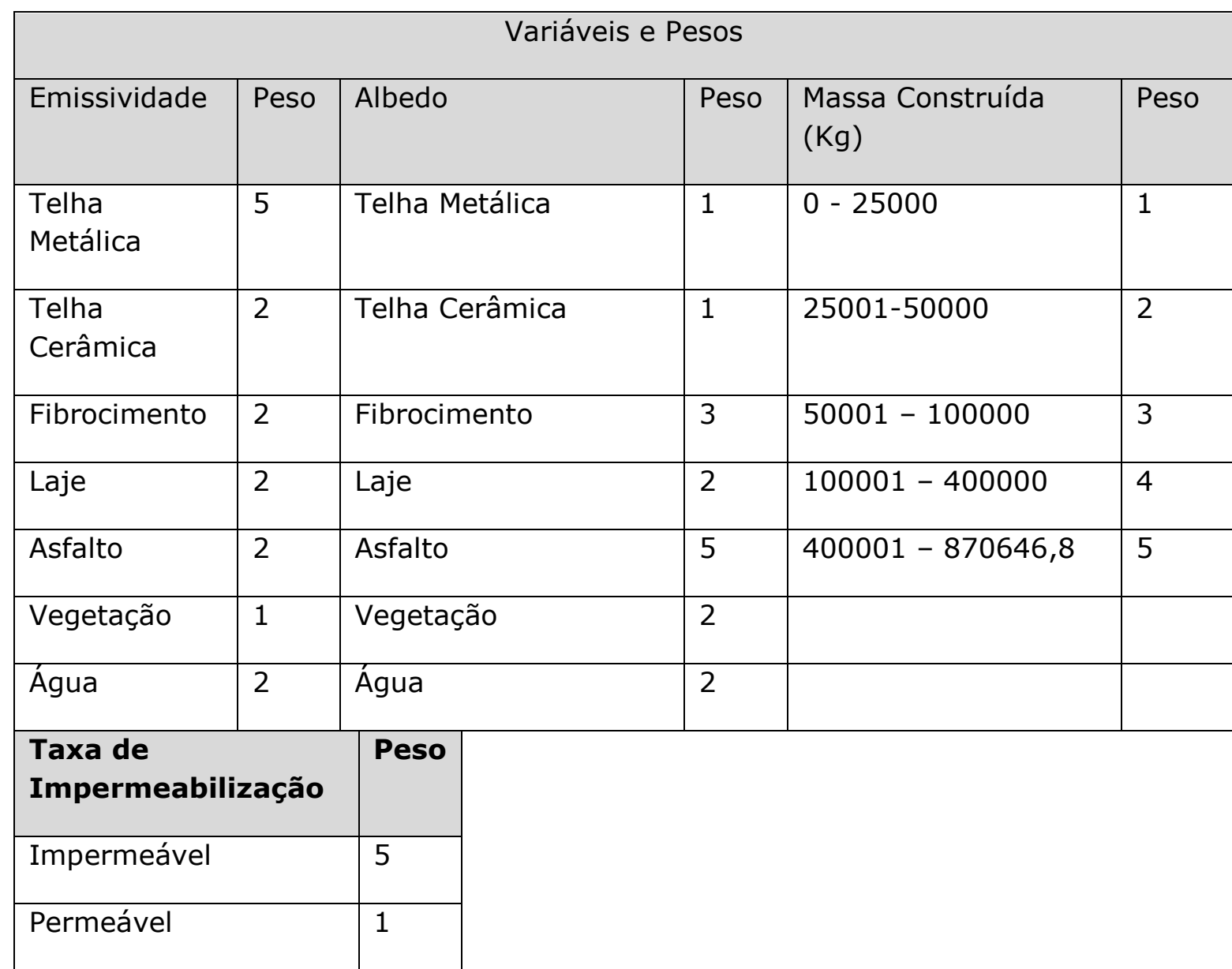

Fonte: Adaptado de Ferreira (2014)

Gartland (2010), explica que telhas metálicas podem chegar a uma temperatura de até $57,9^{\circ} \mathrm{C}$ sob o sol, com um albedo de 0,57 e estas, mesmo apresentando um albedo mais alto, alcançam uma temperatura elevada em função da baixa emissividade. Dessa forma uma telha metálica terá um peso muito maior (5), do que a vegetação (1). As superfícies com camada de asfalto receberão maior peso em função da sua alta capacidade de absorção de calor.

Ferreira (2014 p.59) afirma que o desenvolvimento do modelo matemático proposto consiste em uma integração teórica, quantitativa e qualitativa, afim de obter uma identificação de áreas potencialmente quentes ou frias, em função da disposição das variáveis mais representativas em sua capacidade de amenizar ou potencializar a formação de ilhas de calor.

Depois de somado os pesos, eles foram separados em intervalos qualitativos conforme o quadro 5, dando origem ao mapa de Potencial de Aquecimento. 
QUADRO 5 - Classificação dos pesos quanto ao Potencial de Aquecimento.

\begin{tabular}{|l|l|}
\hline \multicolumn{1}{|c|}{ Soma dos Pesos } & \multicolumn{1}{|c|}{ Potencial de Aquecimento } \\
\hline $1-3$ & Baixo \\
\hline $4-6$ & Médio \\
\hline $7-10$ & Alto \\
\hline$<11$ & Altíssimo \\
\hline
\end{tabular}

\subsection{ELABORAÇÃO DO MAPEAMENTO TERMAL}

A terceira etapa consistiu em um levantamento da temperatura de superfície através de imagens de satélite, objetivando uma comparação com o banco de dados do ambiente construído. Foram confeccionados mapas com diferentes datas de obtenção de imagem, selecionando para esse trabalho o de melhor qualidade, sem presença de nuvens e de data mais recente. Dessa forma, a imagem do satélite Landsat-8 (OLI e TIRS), datada em 12 de Janeiro de 2015 , da Órbita/Ponto 217/75 obtida por meio do site do Serviço Geológico dos Estados Unidos (United States Geological Survey - USGS). O horário de obtenção da mesma é de aproximadamente 10 horas da manhã do horário local.

As bandas de 1 a 9 do Landsat 8 tem resolução espacial de 30 metros, já as bandas 10 e 11 da faixa do infravermelho termal tem resolução espacial de 100 metros, mas são reajustadas para 30 metros para coincidir com a resolução das outras bandas. Dessa forma, Novo (2008) explica que uma imagem que detêm uma resolução de 30 metros, como é o caso do Landsat, não vai distinguir alvos em distâncias entre si menores que 30 metros. Isso deixa claro que haverá um grau de generalização no processo de mapeamento de temperatura de superfície. Ou seja, quanto menor a resolução espacial maior a capacidade de distinção de alvos muito próximos.

Após o registro no site do serviço geológico americano, foi feito o download das imagens em formato GEOTIFF disponíveis para a área de estudo levando em consideração a inexistência de nuvens na mesma. As imagens foram adicionadas no ambiente Arcmap, foram reprojetadas para o Hemisfério Sul utilizando a Projeção\Datum WGS1984\UTM \zona 23S, utilizando o Projetor de Raster inserido no ArcToolbox. Os fundamentos do sensoriamento remoto termal são embasados na termodinâmica clássica que apresenta equações que permitem estabelecer uma relação entre a radiância espectral presentes em imagens do satélite Landsat $8 \mathrm{com}$ valores temperaturas, permitido assim o monitoramento termal de alguma região através da medida indireta de radiação.

Utilizando a ferramenta raster calculator, presente no software ArcGis, foram implementadas as equações (3) e (4) disponibilizadas por Santos et al (2014).

Em seguida foi feita a conversão de números digitais para radiância espectral no topo da atmosfera, utilizando a equação 3:

Eq.(3) $L \lambda=M_{L} * Q_{c a l}+A_{L}$

Em que: 
$L \lambda=$ Radiância expectral no topo da atmosfera (unidade: Watts/( $\mathrm{m}^{2} \mathrm{srd}$ $\mu \mathrm{m}))$;

$$
\begin{aligned}
& M_{L}=\text { Fator multiplicativo de redimensionamento da banda; } \\
& Q_{c a l}=\text { Número Digital (ND) do pixel; } \\
& A_{L}=\text { Fator adi tivo reescalonado de radiância para a banda específica( }
\end{aligned}
$$

Banda 10 e $11=0.10000$

A equação 4 mostra a relação entre a radiância espectral e temperatura:

$$
\text { Eq.(4) } \operatorname{Tr} a d=\frac{K_{2}}{\ln \left(\frac{K_{1}}{L \lambda}+1\right)}
$$

\section{Em que:}

Trad $=$ Representa a temperatura de brilho no sensor ou temperatura radiante que não leva em consideração os aspectos da atmosfera terrestre em Kelvin, ou seja, a temperatura vista do satélite e não a que realmente está na superfície da terra;

$$
\begin{aligned}
& K_{2}=\text { Constante de calibração } 2=1321,08(\mathrm{~K}) \\
& K_{1}=\text { Constante de calibração } 1=774,89(\mathrm{~K}) . \\
& L \lambda=\text { a radiância espectral no topo da atmosfera em } \mathrm{Watts} / \mathrm{m}^{2} \mathrm{srd} \mu \mathrm{m} \text { que }
\end{aligned}
$$
foi obtida através da equação 3.

Depois de gerado o mapa de temperatura de superfície, foi recortada a área de interesse, utilizando a ferramenta Extract by Mask presente no ArcToolbox, em seguida o mesmo foi reclassificado em 6 classes de distribuição de temperatura de superfície.

\subsubsection{CONDIÇÕES ATMOSFÉRICAS ATUANTES NA DATA DE AQUISIÇÃO DA IMAGEM LANDSAT 8.}

De acordo com as cartas sinóticas disponibilizadas pelo site da Marinha, no dia 12/01/2015, a área de estudo estava sob a influência de um o sistema de alta pressão atmosférica, consequentemente ocasionando baixa velocidade do vento, baixa umidade relativa do ar, baixa nebulosidade e ausência de precipitação, sendo assim têm-se uma maior concentração de materiais particulados na atmosfera, o que cria as condições ideais para a investigação do fenômeno ilhas de calor. De acordo com os estudos de Gartland (2010) o efeito 
da ilha de calor será muito mais intenso em dias calmos e claros, uma vez que mais energia solar é capturada durante dias claros, e os ventos mais brandos removem o calor de maneira mais vagarosa, fazendo com que o fenômeno ilha de calor se torne mais intenso.

\subsection{CORRELAÇÃo ESTATÍSTICA VARIÁVEL QUALITATIVA $X$ QUANTITATIVA}

Para fins de validação estatística das informações qualitativas apresentadas pelo mapa de potencial de aquecimento e os intervalos reais quantitativos apresentados pelo mapa de temperatura de superfície optou-se por um modelo de correlação entre os dois mapas. Além de estarmos trabalhando com variáveis de natureza diferente, ainda existe a disparidade na escala, pois o mapa de potencial apresenta uma escala local, altamente detalhada, enquanto o mapa de temperatura de superfície apresenta uma escala regional com um considerável grau de generalização. Assim se optou por essa correlação para se ter um grau de confiabilidade no modelo matemático utilizado, averiguando se os dois mapas apresentaram similaridades entre si.

Dessa forma foi criado um shapefile de pontos que foi adicionado em um projeto do Arcgis contendo o shapefile das 35 regiões urbanas, assim pontos aleatórios foram marcados nessas Ru's. Em seguida foi adicionado o arquivo também em shapefile das informações geradas para o potencial de aquecimento. Assim cada ponto foi identificado quanto o seu potencial de aquecimento: baixo, médio, alto ou altíssimo. Essas informações foram colocadas na tabela de atributos. Para os intervalos de temperatura de superfície foi feita uma média conforme o quadro 6 .

QUADRO 6 - Intervalos de temperatura de superfície correspondentes ao potencial de aquecimento.

\begin{tabular}{|l|l|l|}
\hline \multicolumn{1}{|c|}{$\begin{array}{c}\text { Intervalos de Temperatura de } \\
\text { Superfície }\end{array}$} & \multicolumn{1}{|c|}{ Média } & \multicolumn{1}{|c|}{ Potencial } \\
\hline $24,6-28,2$ & 26,4 & Baixo \\
\hline $28,3-31,2$ & 29,75 & Médio \\
\hline $31,3-32,8$ & 32,05 & Alto \\
\hline $32,9-36,9$ & 34,9 & Altíssimo \\
\hline
\end{tabular}

Em seguida foi adicionado ao projeto o arquivo em raster contendo as informações de temperatura de superfície. Assim foi sendo preenchida a tabela de atributos de acordo com as informações de temperatura média de superfície onde cada ponto estava localizado. Em seguida foram gerados gráficos de acertos e erros para cada intervalo qualitativo de aquecimento.

Por fim, foi aplicado o Coeficiente de Correlação Linear de Pearson, que vai medir o grau de associação linear existente entre duas variáveis quantitativas $x$ e $y$. Esse coeficiente é um índice adimensional com valores que situados entre 1 e -1 . Quando a correlação entre as duas variáveis for máximo, isto é, todos as variáveis serem igualmente idênticas $(x=y)$, o coeficiente de 
correlação será igual a 1. E se ao contrário disso, todas as variáveis não apresentar nenhuma correlação entre si, sendo totalmente independente (não linear), o coeficiente de correlação será igual à zero. Ainda se existir uma correlação negativa máxima entre as duas variáveis, ou seja, à medida que uma aumenta a outra diminui, tem-se um valor de correlação igual a -1.

Dessa forma, as médias obtidas pelo mapa de temperatura de superfície representaram o eixo $x$ e as médias obtidas pelo mapa de potencial de aquecimento representaram o eixo $y$, esses valores foram adicionados no software Matlab ® 2015, onde a equação de Pearson foi aplicada.

\section{RESULTADOS E DISCUSSÃO}

A seguir será apresentado o mapa síntese das variáveis urbanas com o potencial de aquecimento e o mapa da temperatura de superfície para fins de correlação.

O Mapa de Potencial de Aquecimento (mapa 3) está distribuído em quatro classes qualitativas levando em consideração a capacidade de aquecimento conforme a combinação das variáveis analisadas. O mesmo ilustra qualitativamente as áreas propensas à formação de ilhas de calor, a região urbana Centro. Devido ao adensamento, verificado pela intensa massa construída, elevada verticalização o que reduz o fator de visão do céu, formando cânions urbanos, aprisionando o calor.

Observou-se um eixo de potencial formação de ilhas de calor ao longo da Avenida Juscelino Kubitscheck, principal via de ligação da Região Urbana Centro ao Distrito Industrial, o que pode ser atribuído à intensa circulação de veículos tanto leves como pesados. Além disso, é nítida a intensa utilização de coberturas metálicas em grandes galpões dispostos ás margens desse importante via de escoamento. 


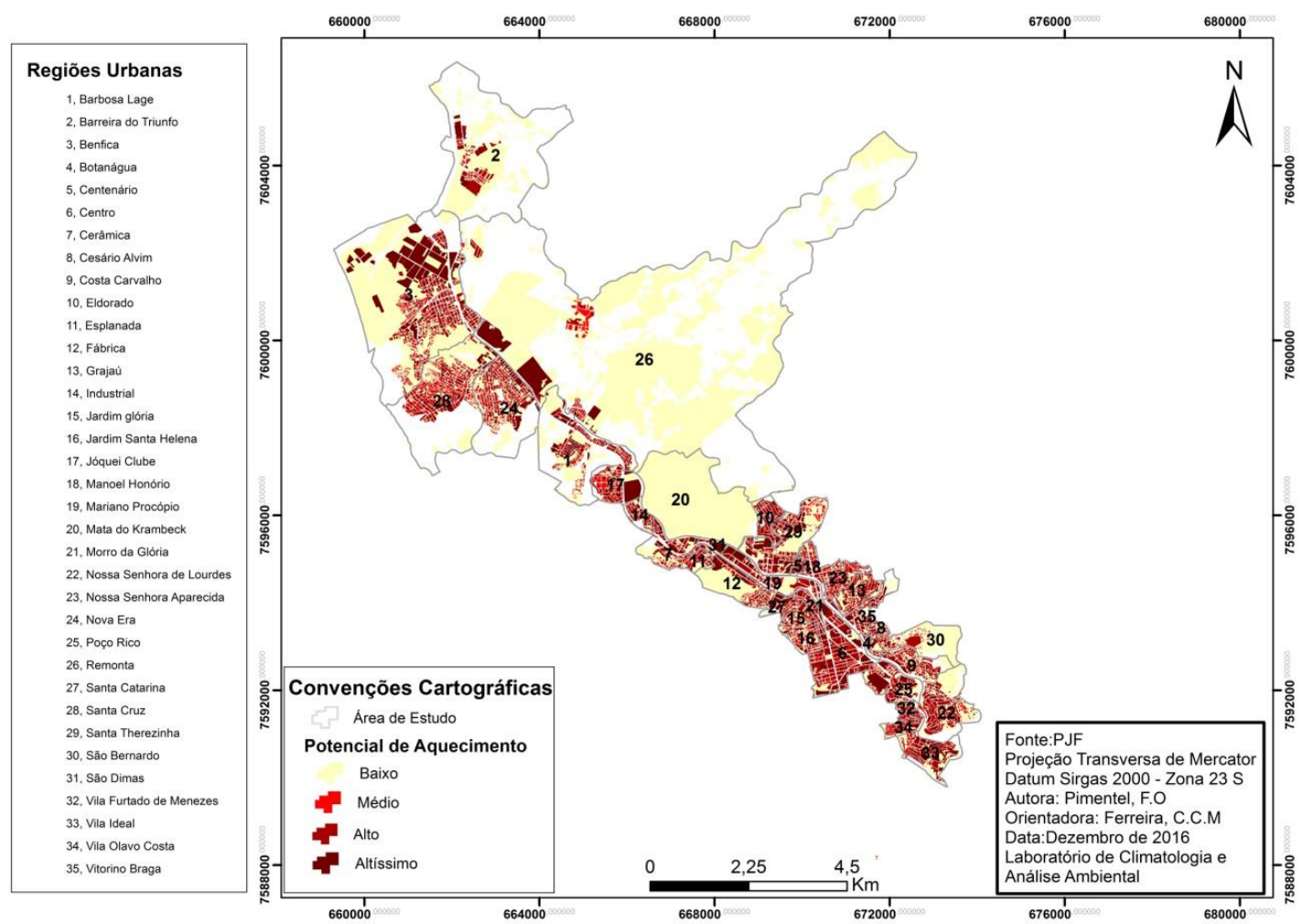

MAPA 3- Potencial de Aquecimento

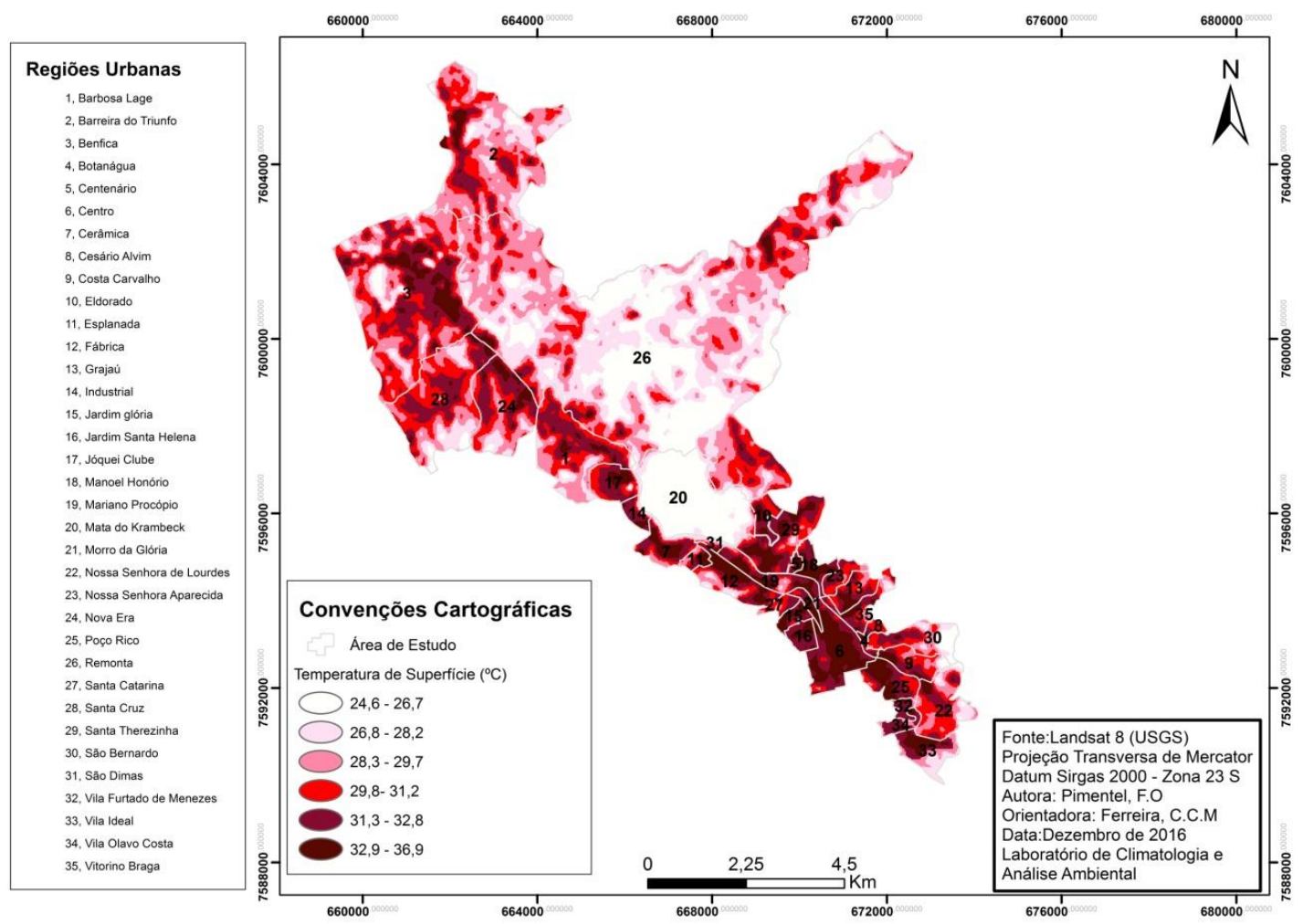

MAPA 4 - Temperatura de Superfície 
Para fins de correlação entre os dois mapas (Mapa 3 e Mapa 4) foi feito um teste de acertos que está apresentado no gráfico 4 . Utilizando o Coeficiente de Correlação Linear de Pearson, para relacionar os dados de temperatura do mapa de Potencial de Aquecimento com os dados de Temperatura de Superfície obteve um aproveitamento de 0,83. Considerando que o coeficiente varia entre 1 e -1 , e quanto mais próximo de 1 maior o grau de correlação, significa que o modelo proposto para a identificação de áreas potencialmente quentes foi similar a realidade.

Para os 27 pontos aleatórios que identificaram as áreas com baixo potencial de aquecimento, apenas 1 não correspondeu no mapa de temperatura de superfície. Nos 22 pontos aleatórios que sobrepuseram às áreas de médio potencial de aquecimento o erro foi maior, 3 pontos apresentaram baixo potencial e outros 6 identificaram altíssimo potencial. Para os pontos de alto potencial de aquecimento, foi o intervalo que demonstrou maior erro de correlação, dos 27 pontos, apenas 12 corresponderam, 11 pontos identificados de alto potencial no mapa qualitativo se mostrou altíssimo no mapa de temperatura de superfície, enquanto 1 se mostrou médio e os outros 3 se mostraram baixo. Os 34 pontos incidentes sobre as áreas de altíssimo potencial de aquecimento, apenas 2 identificaram sendo de alto potencial no mapa de temperatura de superfície, demonstrando portanto menor erro nesse intervalo. Os erros podem ser explicados pelo fato que a modelagem utilizada não leva em consideração as áreas de influências. Em contrapartida o mapa de temperatura de superfície utiliza algoritmos que fazem a mediana entre uma área de alta temperatura e uma área de baixa. Dessa forma no mapa de temperatura de superfície sempre terá as áreas de transição, no modelo proposto que deu origem ao mapa de potencial de aquecimento, não existem essas áreas medianas, a transição vai ser direta.

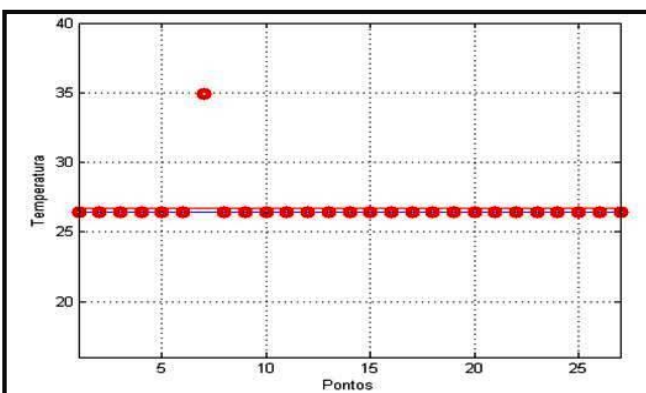

1 - Pontos de Baixo Potencial de Aquecimento

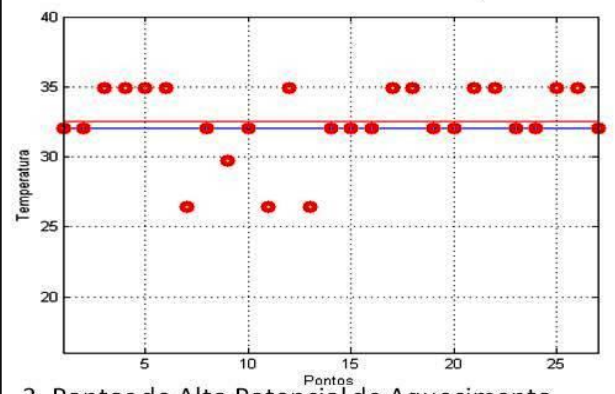

3- Pontos de Alto Potencial de Aquecimento

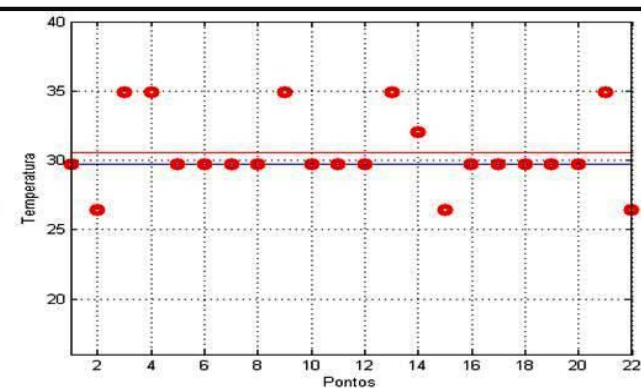

2 -Pontos de Médio Potencial de Aquecimento

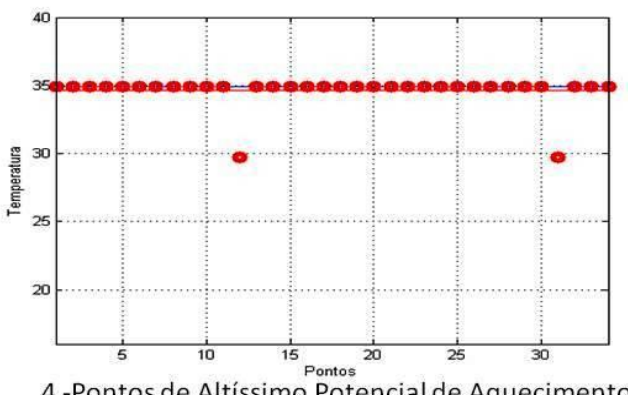

4 -Pontos de Altíssimo Potencial de Aquecimento

GRÁFICO 1 - Distribuição dos pontos no Mapa de Potencial e Temperatura de Superfície 
O resultado apresentado pelo mapa de temperatura de superfície mostra que o Centro da cidade de Juiz de Fora apresenta as temperaturas mais elevadas. Sendo as duas únicas áreas que irão apresentar diferencial térmico é referente ao Parque Halfeld e o fragmento de vegetação localizado no Colégio dos Jesuítas. Porém, na medida em que se vai aproximando da periferia a temperatura de superfície não diminui drasticamente, pelo contrário, ela se mantém elevada em algumas áreas. Esse comportamento pode ser explicado pelo fato de ter siso utilizado a temperatura de superfície e não do ar, e também pela organização da periferia urbana brasileira, que também vai ser adensada se configurando como subcentros como é o caso da região urbana Benfica.

As áreas de menor temperatura de superfície apresentadas no mapa 2, claramente estão associadas à presença de vegetação e consequentemente as áreas identificadas como com menor potencial de aquecimento

\section{CONCLUSÕES}

O presente estudo veio confirmar a existência de áreas propensas a formação ilhas de calor de superfície em Juiz de Fora, pois de acordo com o mapa 3, foi encontrada uma amplitude térmica entre as áreas mais frias e mais aquecidas de $12,3^{\circ} \mathrm{C}$. Notadamente durante o verão, já que a imagem de satélite data do mês de Janeiro.

Em relação à concentração das maiores temperaturas, a região central ficou em destaque, evidenciando os efeitos da urbanização, desencadeada pelos diferentes usos e ocupação da terra no meio urbano sob o clima local. A tendência dos grandes e médios centros é a diminuição da cobertura vegetal à medida que as áreas urbanas vão se expandindo. É sabido que a vegetação tem capacidade de atenuação das características do clima urbano, criando microclimas diferenciados, e propiciando a formação de ilhas de frescor. Apesar da intensidade das maiores temperaturas terem sido encontradas na região central, houve temperaturas elevadas distribuídas por toda a área de estudo.

A existência dos fragmentos de áreas verdes no meio urbano explicitou a influência na amenização das temperaturas, fato que deveria ser levado em conta pelos gestores do planejamento urbano do município, não somente como mero efeito paisagístico, mas no condicionamento do conforto térmico, o que permite promover qualidade de vida e uma maior eficiência energética.

O sensoriamento remoto através da utilização de imagens de satélites para o mapeamento termal de superfície intraurbano se mostrou mais um aliado para as investigações do clima urbano. Pois vai permitir a realização de levantamentos de dados em áreas extensas, proporcionando análises temporais em um recorte espacial. E ainda almeja suprir a falta de dados em determinadas localidades, ou que até existem, mas não estão disponíveis para o uso da comunidade científica.

Porém a dificuldade em trabalhar com dados orbitais é que a escolha da data de obtenção dos produtos vai depender da ausência de nuvens na área de estudo. Exemplo ocorrido na realização dessa pesquisa, o mapeamento é de 2015, pois não foram encontradas imagens de boa qualidade para datas mais recentes. Além disso, existe a questão da escala, a qual se constitui em um obstáculo para uma análise mais detalhada, uma vez que, as imagens 
disponibilizadas gratuitamente ainda são de pequeno detalhamento, na escala de aproximadamente de 1: 30.000.

O mapa de potencial de aquecimento foi construído com base em informações locais. Enquanto o mapa de temperatura de superfície faz generalizações com informações inferiores a 30 metros, o mapa de potencial leva em consideração informações com alto nível de detalhamento, na escala de 1:2000 (imagem aerofotográfica) e obtenção de dados locai na escala de 1:1 (Google Street View). Porém mesmo com essa diferença considerável nos tipos de escalas, o resultado entre os mapas de potencial de aquecimento e o mapa de temperatura de superfície se mostrou correlato. Uma vez que o índice de correlação de Person apresentou uma equiparidade de 0,83, portanto satisfatório.

A utilização da modelagem matemática se mostrou eficiente no sentido em que foi capaz de integrar elementos presentes no meio urbano que de maneira nenhuma devem ser analisados separadamente. Como foi lucidamente ressaltado por Monteiro (2015). O modelo utilizado provou possuir consistência para ser adaptado a fim de ser replicado em diferentes cidades com especificidades térmicas além de ser viável a integração de outras informações e dados.

As variáveis escolhidas (massa construída, albedo, emissividade, fragmentos de vegetação) para compor o modelo matemático tiveram grande correspondência na criação de campos térmicos distintos. Nesse sentido ressalta-se a importância de políticas de planejamento na organização da ocupação urbana. Em áreas com alta densidade de ocupação deve se ter a preocupação com a manutenção ou criação de áreas verdes, aumentando o sombreamento, a própria adoção de coberturas mais frescas, são medidas que proporcionariam melhores níveis de conforto térmico a população.

Vale destacar que a utilização do Sistema de Informação Geográfica foi fundamental no processo de análise e geração dos mapas básicos, temáticos que facilitou a integração das informações de caráter quantitativo e qualitativo.

\section{REFERÊNCIAS BIBLIOGRÁFICAS}

ASSIS, D. C. O Conforto Térmico Associado às Variáveis de Cobertura da Terra na Região Central de Juiz de Fora - MG. Dissertação de Mestrado, UFJF, Juiz de Fora, 2016.

FERREIRA, C. C. M. Estudo do Comportamento Chuvoso em Juiz de Fora. Revista Geonorte, edição especial, p.953-963, Manaus, 2012.

FERREIRA, C. C. M. Modelo para Análise de Variáveis de Cobertura da Terra e a Identificação de Microclimas, em Centros Urbanos. Revista Brasileira de Climatologia, v.14, p.50-75, jan-jul, 2014.

FERREIRA, C. C. M; ASSIS, D. C. O mapeamento do albedo e análise de sua influência na caracterização de áreas urbanas. In: Experimentos em Climatologia Geográfica. 2014.

FITZ, P. R. Cartografia Básica. São Paulo: Oficina de Textos, 2008. 
FITZ, P. R. Geoprocessamento sem complicação. São Paulo: Oficina de Textos, 2008.

GARCIA, M. C. M. Una Propuesta de Terminologia Castellana em Climatologia Urbana. Investigaciones Geográficas, n 17, p. 89 -97, 1997.

GARTLAND, L. Ilhas de Calor: como mitigar zonas de calor em áreas urbanas. São Paulo: Oficina de Textos, 2010.

GRIMMOND, C. S. B., 2006, Progress in measuring and observing the urban atmosphere.Theoretical and Applied Climatology, vol. 84, p. 3-22, 2006.

IBGE. Instituto Brasileiro de Geografia e Estatística. Disponível em http://www.ibge.gov.br/home/

IPPLAN/JF. Plano Diretor de Desenvolvimento Urbano de Juiz de Fora. Juiz de Fora: IPPLAN, 2000.

MENDONÇA, F.; DANNI-OLIVEIRA, I. M. Climatologia: Noções Básicas e Climas do Brasil. São Paulo: Editora Oficina de Textos, 2007.

MENDONÇA, F; DUBREUIL, V. Termografia de superfície e temperatura do ar na RMC(região metropolitana de curitiba/PR). RA 'E GA. n. 9, p. 25-35, 2005.

MENDONÇA, F. O Estudo do Clima Urbano no Brasil: Evolução, tendências e desafios. In: MONTEIRO, C.A.F. \& MENDONÇA, F. (Org.) Clima Urbano. São Paulo: Editora Contexto, 2003.

MONTEIRO, A. O clima urbano do Porto: contribuição para a definição das estratégias de planejamento e ordenamento do território. Lisboa: Fundação Calouste Gulbenkion/Junta Nacional de Investigação Científica e Tecnológica, 1997.

MONTEIRO, C. A. F. Da necessidade de um caráter genético à classificação climática. Revista Geográfica, Rio de Janeiro, v. 31, n. 57, p. 29-44, 1962.

MONTEIRO, C. A. F. Análise rítmica em climatologia. Climatologia, São Paulo: IGEOG/USP, n.1, 1971.

MONTEIRO, C. A. F.; MENDONÇA, F. Clima Urbano. São Paulo: Editora Contexto, 1976.

MONTEIRO, C. A. F. Clima e excepcionalismo: conjecturas sobre o desempenho da atmosfera como fenômeno geográfico. Florianópolis: UFSC, 1991. 241p.

MONTEIRO, C. A. F. A cidade como processo derivador ambiental e estrutura geradora de um "clima urbano". Geosul, Florianópolis, v.5, n.9, p. 80-114, janjun, 1991.

MONTEIRO, C. A. F. A; SANT' ANNA NETO, J. L; MENDONÇA, F. A; ZAVATTINI, J. A. A Construção da Climatologia Geográfica no Brasil. Campinas, Editora: Alínea, 2015.

NOVO E. M. L. M. Sensoriamento Remoto: Princípios e Aplicações. 2a ed., São Paulo: Editora Edgard Blücher Ltda., 2008.

PREFEITURA DE JUIZ DE FORA. Juiz de Fora Sempre. Plano Diretor de Desenvolvimento Urbano de Juiz de Fora. Juiz de Fora (MG): FUNALFA Edições, 2004 
SANTOS, A. R. et al. Sensoriamento Remoto no ArcGis 10.2.2 Passo a Passo: Processamento de Imagens Orbitais - Volume 1.Alegre: Caufes, 2014.

TSO, C. P. et al. An improvement to Energy Balance Model for Urban Thermal Environment Analysis. Energy and Buildings, n. 14, p. 143-152, 1990.

USGS. Serviço Geológico dos Estados Unidos. Disponível em: <http://glovis.usgs.gov/> Acesso em: Janeiro de 2016. 